\title{
A MUNDIALIZAÇÃO DO CAPITAL E SEUS IMPACTOS SOBRE O PROCESSO DE TRABALHO E A EDUCAÇÃO
}

\author{
Thayene da Costa Campos Santos ${ }^{1}$ \\ Thaylla Soares Paixão ${ }^{2}$
}

\section{RESUMO}

O presente artigo tem por objetivo discutir acerca da nova fase de internacionalização capitalista - expressa pela mundialização do capital - e os possíveis impactos da mesma para o âmbito do trabalho e para a educação. Assim, o intuito é promover uma reflexão acerca das modificações incididas sobre o trabalho e a educação escolar, com ênfase na gestão educacional, tendo em vista o projeto hegemônico neoliberal que caracteriza a contemporaneidade. A discussão acerca da reestruturação produtiva enquanto um dos processos que integra a mundialização do capital se faz imprescindível para compreender tais mudanças. O presente trabalho utiliza de aportes teóricos embasados em autores marxistas, os quais nos permitiram compreender a realidade concreta de forma orgânica e complexa, tendo em vista a totalidade da mesma. Almejamos através do artigo aqui exposto construir conhecimentos que permitam a classe trabalhadora desenvolver uma leitura crítica sobre a atual configuração do trabalho e da educação, bem como auxiliar esta mesma classe na luta pela transformação das relações sociais de exploração e de dominação vigentes.

Palavras-chave: mundialização do capital; neoliberalismo; trabalho; educação; gestão escolar.

\section{GLOBALIZATION OF CAPITAL AND ITS IMPACTS ON THE PROCESS OF WORK AND EDUCATION}

\begin{abstract}
This article aims to discuss about the new phase of capitalist globalization - expressed by the globalization of capital - and the possible impacts of the same for the scope of work and education. Thus, the intention is to promote a reflection about the incisive changes about work and school education, with an emphasis on educational management, in view of the neoliberal hegemonic project that features contemporary. The discussion about the restructuring process as one of the processes that integrates the globalization of capital is indispensable to understand these changes. This paper uses the theoretical framework grounded in marxist authors, which made possible for us to understand the reality of an organic and complex, considering the totality of it. We aim through the article here exposed build knowledge which permits the work class develop a critical reading of the current configuration of work and education, as well as assisting this same class in the struggle for the transformation of the social relations of exploitation and domination force. Keywords: globalization of capital; neoliberalism; job; education; school management.
\end{abstract}

\section{Introdução}

O atual contexto do sistema capitalista é perpassado por mudanças que afetam o modo de produção, a condição do trabalho e o perfil de diversas organizações sociais, com destaque para a instituição escolar. 
Tais modificações estão relacionadas às estratégias empregadas pela classe dominante em meados dos anos 1980 para a superação da crise estrutural do capital, $^{3}$ ocorrida na década de 1970, que teve como marco significativo a queda expressiva das taxas de lucro (BEHRING, 2008). Este período sinalizou, por um lado, o esgotamento das formas de acumulação da produção de natureza fordista, e por outro, permitiu a burguesia desenvolver sua consciência acerca da capacidade de controle sobre as crises cíclicas do capitalismo (SAVIANI, 2005).

As táticas empreendidas pela classe burguesa para a superação da referida crise implicaram concomitantemente a alteração do modelo de organização do trabalho e da produção e a criação de um conjunto de valores e normas capazes de alavancar a dimensão humana para o aumento da produtividade, bem como para uma maior obtenção de lucro (ANTUNES, 2001).

Elas passaram a orientar uma nova forma de organizar o trabalho e a educação na sociedade atual: trabalho torna-se cada vez mais alienado e explorado e a educação passa a ser vista como uma mera mercadoria, incorporando padrões empresariais ao plano educacional, o que fez emergir uma nova cultura escolar. Além disso, surgem novas demandas de formação para o trabalhador, cuja finalidade é permitir que este possa se adequar às mudanças da sociabilidade capitalista, dissolvendo as dimensões ontológicas da educação e do trabalho, tal como propõe a visão marxista.

É nesse sentido que o presente texto tem por objetivo discutir acerca do processo contraditório e excludente que caracteriza a nova fase de internacionalização capitalista, a qual Chesnais (1997 apud MELO, 2004) chamou de mundialização do capital, sendo esta orientada pelo projeto neoliberal. Além disso, pretendemos refletir a respeito dos impactos de tal processo no âmbito do trabalho e da educação, neste último especificamente no que concerne a gestão escolar.

Para fundamentar o nosso estudo, centraremos nossas reflexões nas categorias de trabalho e educação em Marx, duas atividades especificamente humanas que são inerentes ao processo de produção e reprodução da vida e, também, em estudos teóricos de autores renomados que buscam pesquisar e refletir sobre o modelo de produção capitalista e seus reflexos, bem como em pesquisadores que discutem a conjuntura social, econômica, política e educacional no âmbito da nova sociabilidade burguesa.

Assim, as páginas que compõem esse trabalho estão divididas em três partes centrais, além dessa introdução e da conclusão. Na primeira fazemos uma apreciação sobre o caráter ontológico do trabalho e da educação a partir de uma perspectiva marxista. Realizamos, também, uma discussão acerca da concepção crítica de organização escolar, pautada na transformação social. Na segunda, nos dedicamos a discorrer a respeito do processo de reestruturação capitalista, mais conhecido por mundialização do capital, bem como sobre o projeto neoliberal de sociedade, expondo de modo elucidativo os princípios liberais que fundamentam o neoliberalismo. Já na terceira parte, tecemos considerações sobre a reestruturação produtiva, explicitando seus aspectos conceituais e estruturais que surgem na esteira da mundialização do capital e do avanço do neoliberalismo. Nesta seção apresentamos reflexões acerca desse processo, indicando as implicações que essa nova forma de acumulação capitalista traz para o mundo do trabalho, para a educação escolar e, inclusive, para a subjetividade do sujeito, isto é para a formação humana.

Esperamos que as análises empreendidas nesse artigo possam ampliar o conhecimento sobre o processo de mundialização do capital, considerando a sua repercussão no trabalho e na educação, pretendendo contribuir para a construção de conhecimentos que fortaleçam o debate sobre o tema em questão. 


\section{Reflexão preliminar: o trabalho e a educação na perspectiva ontológica}

Segundo a perspectiva marxiana, o trabalho consiste em uma atividade especificamente humana adequada a um fim, que tem a potencialidade de humanizar os sujeitos. Ele se caracteriza como elemento central para a formação do ser social, sendo compreendido como um "processo entre o homem e a Natureza, um [ato] em que o homem, por sua própria ação, media, regula e controla seu metabolismo com a Natureza" (MARX apud TUMOLO, 2005, p. 246).

No trabalho o homem coloca em movimento toda a sua organização biológica pernas, braços, mãos, cabeça - com vistas a transformar a natureza e dela extrair os meios necessários para o seu próprio sustento. Ao modificar a natureza, o homem se autotransforma, humanizando o mundo natural, refinando suas capacidades físicas e intelectuais, produzindo e reproduzindo a sua própria existência.

Este processo não se faz de forma aleatória, mas se dá de modo racional, visto que o ser humano estabelece objetivos, cria valores e planeja ações para a superação de sua condição precedente, se diferenciando dos demais animais por essa capacidade de projetar intencionalmente iniciativas.

A dinâmica da atividade humana envolve, segundo Marx (apud SAVIANI, 2006) e Duarte (2003), uma relação dialética entre os processos de objetivação e a apropriação dos resultados dessa objetivação. A apropriação surge a partir da relação entre o homem e a natureza, em que o primeiro se apropria da segunda, incorporando-a à prática social.

A objetivação ocorre de forma simultânea a este processo, visto que o homem produz uma realidade objetiva que é portadora de características humanas e socioculturais, estando nela presentes atividades de gerações de seres humanos. Isso implicará a necessidade de outras formas de apropriação e, por conseguinte, de objetivação, ocasionando um processo sem fim. A relação entre a apropriação da atividade humana objetivada produz riquezas objetivas e subjetivas, devendo essas serem compartilhadas igualmente por todos os sujeitos (DUARTE, 2003).

Na perspectiva marxista, o trabalho deve permitir o desenvolvimento da totalidade dos seres humanos, bem como a emancipação e a libertação dos mesmos. Asbahr e Sanches (2006), afirmam que esta atividade vital deve se constituir enquanto:

Uma atividade libertadora da humanidade, pois tem como característica propiciar a transcendência da condição natural. Ao superar a natureza por meio do trabalho e por ser ético, ser de vontade, o homem constrói sua história. Não sendo indiferente ao mundo que rodeia, torna-se sujeito, agente da história (p. 58).

Assim, enquanto atividade libertadora torna-se imprescindível que a finalidade e os meios de execução do trabalho estejam sob domínio do ser humano, e o produto do trabalho, entendido como realização do sujeito, deve pertencer ao trabalhador (ASBAHR; SANCHES, 2006). Isso significa que a atividade humana, composta pelos meios de produção e pela força de trabalho, não deve ser apropriado de forma privada por uma parcela específica da sociedade, não devendo também ocasionar ao operário a expropriação de seus meios de vida e a venda de sua força de trabalho, fatores que ocorrem na sociedade capitalista (PARO, 2001).

Da mesma forma que o trabalho, a educação também consiste em uma atividade especificamente humana. Ambos estão intrinsecamente relacionados, sendo a educação "uma exigência do e para o processo de trabalho, bem como é, ela própria um processo de trabalho" (SAVIANI, 2012, p. 11). 
É através do trabalho que o homem também produz cultura. Esta envolve todo o saber produzido historicamente, ou seja, os conhecimentos científicos/sistematizados e os demais tipos de conhecimento produzidos pela humanidade, incluindo os valores, as técnicas, a arte, os comportamentos, entre outros (ASBAHR; SANCHES, 2006). A educação consiste, pois, no processo de transmissão e assimilação da cultura historicamente produzida, sendo, assim, a "atualização histórica de cada indivíduo" (PARO 2001, p. 21). Ela não se configura enquanto um ato neutro, visto que pode ser carregadora de diferentes intencionalidades, logo não se constitui como um produto acabado, mas se constrói a partir de relações e embates entre os sujeitos sociais.

A relação entre trabalho e educação se configura como uma relação de identidade, que além de possibilitar o desenvolvimento pleno do ser humano, se constitui como um instrumento de emancipação humana e de transformação social. Na concepção marxista, o trabalho enquanto princípio educativo tem por finalidade formar ético-politicamente o homem para viver em igualdade social, evitando qualquer tipo de exploração.

Com relação específica ao trabalho pedagógico, verificamos que este se configura enquanto trabalho não material, o qual pode ser de dois tipos, a saber: (1) ocorre a separação entre produção e consumo e (2) ato de produção e consumo são simultâneos. A educação se vincula ao segundo tipo, visto que no ato educativo, professor e aluno produzem juntos os conhecimentos, assim, o educando não se constitui apenas como objeto do trabalho, mas sim como sujeito de sua educação, participando ativamente de seu processo de aprendizagem (SAVIANI, 2012).

A educação, segundo Oliveira (2006), deve ter por objetivo o ser humano educado e para alcançá-lo, torna-se importante o reconhecimento do aluno enquanto ser de vontade e assegurar as condições objetivas de trabalho. Para que o processo de educação se efetive de forma crítica e emancipatória, faz-se necessário uma organização escolar que almeje tais ideais e que contribua para a transformação da personalidade viva do aluno.

Partindo da compreensão de Paro (2001), de que a administração envolve "a utilização racional de recursos para a realização de determinados fins" (p. 45), torna-se necessário que as funções da escola, que abarcam o planejamento, a organização, a direção e o controle, estejam orientadas por um projeto de sociedade e de educação efetivamente democrático e revolucionário. Isso seria possível através de uma educação escolar que concorresse:

para a emancipação do individuo, enquanto cidadão partícipe de uma sociedade democrática, e, ao mesmo tempo, dar-lhe meios, não apenas para sobreviver, mas para viver bem e melhor no usufruto de bens culturais que hoje são privilégio de poucos, então a gestão escolar deve fazer-se de modo a estar em plena coerência com esses objetivos (PARO, 2000, p. 304).

Compreendemos que a filosofia de educação supracitada está comprometida com a formação do homem histórico e que, portanto, ultrapassa a noção embasada na visão de mundo burguesa de que a escola deve ter como propósito a preparação única e exclusiva para o mercado de trabalho. Ao contrário, este ideal de educação está articulado com o objetivo de viver bem, propiciando uma prática educativa que permita ao sujeito usufruir da herança cultural acumulada e a contribuir para a construção da realidade social (PARO, 2000).

A escola, enquanto uma instituição comprometida com a transformação social, deve ter dupla responsabilidade: (1) mediar à formação humana, ao promover de modo sistemático e organizado a educação que permite a atualização histórica dos sujeitos e (2) 
estar sintonizada com um projeto crítico e democrático de educação, sendo essencial garantir a apropriação do saber historicamente acumulado (ASBAHR; SANCHES, 2006). Ressaltamos que a socialização do conhecimento acumulado é fundamental para que a classe trabalhadora possa se emancipar da dominação do capital (NEVES, 1994).

Logo, constatamos que o trabalho e a educação são resultantes da atividade humana, sendo ambos inerentes a existência do homem. Na perspectiva marxista, o ato de trabalho é também um processo educativo ou ontocriativo, que deve permitir o desenvolvimento de todas as potencialidades do sujeito, estando orientado por uma perspectiva de sociedade e de educação pautada na produção da existência a partir da igualdade social e da socialização da riqueza produzida.

As formas que tais processos assumem na realidade concreta dependem da dialética entre o caráter ontológico e o histórico, que envolve um determinado tempo e uma formação social específica. Na sociedade contemporânea, sendo esta marcada pelo projeto neoliberal, a relação trabalho e educação, é tencionada pelos preceitos e práticas políticoideológicas advindos de tal concepção de mundo. No entanto, cumpre registrar que a educação possui uma dupla dimensão, visto que, apesar de tais influências advindas da sociedade capitalista, ela tem o potencial de possibilitar a instrumentalização cultural da classe trabalhadora, configurando-se enquanto uma ferramenta estratégica de contrahegemonia (NEVES, 1994).

\section{A base político-ideológica da mundialização do capital: o projeto neoliberal}

As mudanças conjunturais que vem se sucedendo no âmbito da sociedade, ano após ano, trouxeram novas alterações no modo de organização do trabalho e de produção, nas políticas sociais, bem como nas relações de poder em níveis globais (NEVES; SANT'ANNA, 2005). Essas transformações insurgem do processo de redirecionamento capitalista nos períodos finais do século XX e iniciais do século XXI, expressadas pela mundialização do capital.

No século passado, mais precisamente com o fim da Segunda Guerra Mundial, o capitalismo conheceu uma nova fase de prosperidade econômica, sendo caracterizada por Hobsbawm (1995) como a "Era de Ouro" ou, ainda, como 25 ou trinta anos gloriosos. Tal "Era" foi ajustada pelas políticas keynesianas, que buscavam minimizar as desigualdades sociais e a crise financeira do pós-guerra por meio da subvenção da aparelhagem estatal ${ }^{4}$. Sob o domínio da dominação burguesa, o Estado intervencionista, ou de Bem-estar social, assumiu, nesse período, um papel de educador e legitimador da ordem vigente (MARTINS, 2009).

Esse novo estágio teve como direção político-econômica o governo dos Estados Unidos da América (EUA) que, articulado aos organismos internacionais [Fundo Monetário Internacional (FMI), Banco Interamericano para a Reconstrução e Desenvolvimento, Banco Mundial (BM) e o Acordo Geral de Tarifas e Comércio (GATT)] e ao sistema de produção fordista, deu início a uma nova fase de expansão do capital no pós-guerra, envolvendo mudanças na organização econômica e social.

Entretanto, após quase trinta anos de crescimento prolongado da economia, tem-se um extenso período de recessão e de crise estrutural do modo de produção capitalista. As políticas keynesianas perderam a capacidade de manter o crescimento atingido no pósguerra, provocando elevados níveis de inflação e desemprego, redução das taxas de crescimento e esgotamento do Estado de Bem-estar social, o que levou a burguesia, em seu conjunto, utilizar-se de novas estratégias para solucionar tal crise e manter os seus interesses hegemônicos. 
Dessa forma, iniciou-se um processo de reestruturação do capital mundial e de seu sistema ideológico e político de dominação, o qual serviu para aprofundar as formas de internacionalização vivenciadas historicamente pelas fases do capitalismo. Essa nova fase é caracterizada pela mundialização do capital, iniciada nos meados da década de 1970, que diz respeito a um quadro político e institucional direcionado a edificação de novas formas de acumulação do capital, ou melhor, de uma nova configuração do capitalismo e dos mecanismos que envolvem a sua regulamentação (CHESNAIS, 1996, 1977 apud BERHING, 2008), acompanhado pela introdução da informática e de novas tecnologias veiculadas a microeletrônica.

O processo de mundialização do capital foi se consolidando a partir das iniciativas conduzidas por grandes corporações capitalistas, sendo principalmente chancelado pelo FMI e pelo BM, que objetivavam recuperar as taxas de lucros abaladas pela crise da "Era de Ouro" e, sobretudo, conformar os países dependentes para uma nova sociabilidade. Assim, esses sujeitos políticos coletivos começaram a impor medidas de liberalização e desregulamentação dos mercados de modo a transformar tais países em "prestadores de serviços [...], transferidores de dinheiro a título de pagamento da dívida externa e de suas renegociações para os países centrais" (MELO, 2005, p. 2), acentuando os fatores de hierarquização entre os Estados e Nações, redesenhando a geopolítica mundial.

Em todos os países de capitalismo ocidental a liberalização dos mercados financeiros e demais medidas estruturais apresentavam-se como uma saída frente à crise estrutural do capital, na medida em que facilitavam o financiamento da dívida pública, gerada pelo enfraquecimento das políticas keynesianas e pela incapacidade da classe burguesa de assimilar a sociedade ao seu projeto hegemônico (MARTINS, 2009).

De modo geral, essas medidas contribuíram para que as barreiras e os limites territoriais começassem a se dissolver, abrindo espaço para a expansão dos preceitos elaborados pela Sociedade de Mont Pèlerin, fundada por Friedrich August Von Hayek, em 1947, nos EUA. Tal organização reunia um número significativo de representantes dos mais diversos setores em torno de um "liberalismo renovado" (GROS, 2003) que culminou num articulado projeto societário, denominado de neoliberalismo. Esse novo movimento pode ser compreendido como parte de um projeto hegemônico da burguesia que passou a orientar o reordenamento do capitalismo de acordo com uma visão de mundo voltada para o mercado como alternativa de eliminar todas as barreiras à livre expansão do capital, entre elas os parcos direitos conquistados pelos trabalhadores em períodos anteriores (BEHRING, 2008). Gentili (1996 apud SOUZA, 2011, p. 55) afirma que o "neoliberalismo constitui-se em vigorosas estratégias políticas, jurídicas e econômicas, ordenando um ambicioso projeto de reformas ideológicas".

O novo reordenamento político-econômico se apresentou como alternativa de dominação em substituição ao modelo de Estado de Bem-estar social, sem romper com a lógica do capital, visto que para os neoliberais a crise financeira estava atrelada aos benefícios outorgados aos trabalhadores e à interferência direta e abrangente do Estado sobre as questões sociais. Com efeito, começava a ser instaurada uma nova tendência ideológica em escala global, que se articulou com os novos avanços tecnológicos voltados para o processo de produção.

A ortodoxia neoliberal orientou diversas experiências de governo pelo mundo. $\mathrm{O}$ Chile foi o primeiro país a adotar sensivelmente seus preceitos, no governo ditatorial de Augusto Pinochet, em 1973. Segundo Martins (2009), foi somente nos governos de Thatcher (1979) na Inglaterra, de Reagan (1980) nos EUA e de Khol (1982) na Alemanha que a agenda reformadora do neoliberalismo se consolidou, impondo medidas de ajustes 
econômicos com vistas a aprofundar as condições de financeirização da economia mundial, provocando fortes danos à classe trabalhadora nos anos mais recentes de nossa história.

Como parte do processo de mundialização do capital, vários países da Europa aderiram à doutrina neoliberal, outros, como a França, de Miterrand, ainda tentaram recusar, mas em pouco tempo se viram forçados à adotar medidas alicerçadas ao projeto fundamentado por Hayek. Na América Latina esse programa se efetivou a partir do Consenso de Washington ${ }^{5}$, que buscou orientar os governos de países periféricos na adequação de suas economias às novas regras deliberadas principalmente pelos Organismos Internacionais, entre eles BM e o FMI.

Em que pesem as resistências de uma boa parte dos sujeitos políticos em relação à implementação do projeto neoliberal (MARTINS, 2009), as diretrizes do Consenso de Washington se propagaram, recomendando um conjunto de ajustes estruturais que envolviam basicamente: (1) a privatização de empresas públicas; (2) reforma tributária; (3) redefinição das prioridades do gasto público; (4) flexibilização trabalhista; (5) enfraquecimentos dos sindicatos e (6) desregulação econômica.

As consequências desses ajustes neoliberais para os países da América Latina e Caribe se refletem até os dias atuais, com o aumento da dependência destes em relação às agências financeiras e as nações desenvolvidas, ampliação da desigualdade social, perdas dos parcos direitos sociais conquistados pela classe trabalhadora, elevação do desemprego, exclusão social entre classes e profundas mutações no interior do mundo do trabalho.

Segundo Martins (2009), constituem-se como principais fundamentos do projeto neoliberal de sociedade: (1) o mercado como o agente superior da organização social; (2) individualismo como valor moral radical; (3) a noção de "liberdade" e a (4) minimização da intervenção estatal.

O primeiro refere-se à superioridade do mercado em relação a qualquer tipo de regulação econômica e política e a qualquer instituição social. Na lógica de Hayek, o mercado se constitui como um mecanismo autorregulador da economia e grande estruturador das relações sociais e de políticas sociais. Em outras palavras, ele assume o papel de resguardar a ordem social dos desequilíbrios cíclicos do capitalismo (BIANCHETTI, 2005).

Para Hayek, "diante da correlação de forças presente no mundo, o fundamental era "cortar o mal pela raiz", isto é, combater todos os tipos de "planificação da economia" (MARTINS, 2009, p. 32). Por isso a doutrina neoliberal destrói qualquer força externa que possa atrapalhar o ordenamento ideal de toda a sociedade. É assim que a atuação direta do Estado nas questões sociais e em atividades econômicas passa a ser vista como um entrave desse processo, pois, segundo a lógica hayekiana, somente o conjunto de interesses individuais presentes no mercado seria capaz de solucionar todos os problemas da sociedade, como se houvesse a atuação de uma "mão invisível". Nesses moldes, o mercado é visto como sinônimo de eficiência e agilidade quanto à cobertura de um extenso leque de ações que envolvem a produção de bens e a prestação de serviços públicos.

É sob esse ângulo que a tendência mais recorrente tem sido de aferir as políticas sociais, mais precisamente a educação, como uma mercadoria semelhante a qualquer outra que está à venda. A educação, regida pelas leis mercadológicas, passa a ser entendida como um serviço, negando a ideia de que seja um direito conquistado pelos cidadãos. No padrão de organização neoliberal, ela se constitui como um fator de produtividade e competitividade de mercado.

O segundo princípio neoliberal refere-se ao "individualismo como valor moral radical", sendo este uma importante referência para organizar a sociedade. A noção de individualismo está pautada no pensamento hayekiano de que todo indivíduo é um ser livre 
e soberano, com o poder de decisão sobre os seus próprios interesses e objetivos. Dentro de uma concepção liberal, o ser humano é dotado de qualidades que lhe permitem desenvolver-se de maneira independente, sem interferência social. Nesse sentido, Hayek (apud MARTINS, 2009) defende que todo homem e "sua liberdade deveriam ser o centro de todas as preocupações políticas e econômicas do mundo moderno" (p. 34), isso porque qualquer tipo de manifestação coletiva promoveria a destruição de sua liberdade e a redução de suas potencialidades, isto é, um ocultamento de sua individualidade.

O indivíduo para o neoliberalismo é, portanto, o resultado da "sorte", que determina as suas aptidões e capacidades naturais. É fruto de uma medida arbitrária que estabelece o tipo de família, o meio cultural e as oportunidades que aparecem ao longo da vida sem a intervenção do outro (BIANCHETTI, 2005). É um sujeito "a-histórico" que se move por meio de seu interesse e dispensa a noção de totalidade, diferentemente do pensamento marxista, que procura não separar a constituição do ser social das condições em que está inserido na sociedade, considerando que o homem não se desenvolve sozinho, mas na coletividade, construindo a sua história sob determinadas circunstâncias.

A noção de "individualismo como valor moral radial" propõe que diante dessas circunstâncias "o indivíduo estaria em melhores condições de vida, se não se ocupasse com as tentativas infundadas de controlar e regular o mercado e a sociedade" (MARTINS, 2009, p. 36), pois preservando sua liberdade e autonomia obtém um melhor resultado do que a vontade humana possa prever. Assim, em um ambiente de homens individualistas, inseridos numa economia de livre concorrência, o mercado seria a melhor opção para o desenvolvimento social. Nesse sentido, Hayek indica a necessidade de manter a essência individualista como forma de ordenar e organizar a sociedade, nos moldes neoliberais.

Em síntese, o que "individualismo como valor moral radical" determina é a atomização do indivíduo (MARTINS, 2009, p. 38). Para Hayek, é necessário construir uma consciência política que impossibilita o sujeito compreender o seu papel histórico na sociedade, de modo a não tomar consciência racional da realidade, como se fosse possível isolá-lo da vida social, visando naturalizar as desigualdades, as crises, a exploração do capital sobre o trabalho e os outros problemas que, em geral, emergem do sistema capitalista e que põem em xeque o projeto de mundo defendido pela burguesia.

Entretanto, a noção supracitada começa a sofrer alterações no final do século XX. Face às profundas mudanças que se operaram no cenário mundial o individualismo passa a estimular a participação dos indivíduos em atividades pautadas na cooperação e solidariedade social. Cada sujeito, movido pela sua individualidade, entraria em contato com outro ou pequenos grupos para a realização e participação em processos políticos mais simples, visando um melhor funcionamento do mercado (MARTINS; LIMA, 2005).

Esse "novo individualismo" sugere que as pessoas não devem mais se limitar a receber da sociedade, mas também voltar-se a ela. A proposta visa "convidar" toda a sociedade para atuar e promover ações sociais, tendo sido convencida a estabelecer "troca de favores" sem qualquer tipo de questionamentos e reivindicações aos princípios básicos da nova política de desenvolvimento. Ou seja, o "individualismo como valor moral radical" visa criar uma nova geração de pessoas com iniciativa individual e com o senso de responsabilidade social. ${ }^{6}$

O terceiro fundamento aqui elucidado refere-se à noção de liberdade, pilar sobre o qual se assenta a doutrina neoliberal. Segundo Martins (2009), a liberdade seria o poder supremo ou de origem natural que orienta cada indivíduo a agir conforme o próprio interesse, contanto que seja respeitado o direito à vida, ao lucro e à propriedade. Entretanto, para o seu bom funcionamento, a mesma não deve ser exercida num ambiente onde a coerção, planificação ou a razão humana estejam fortemente presentes, visto que 
tais fatores impossibilitam a evolução do conhecimento humano e, por conseguinte, o retrocesso da sociedade como um todo.

Segundo Stewart Júnior (1995), a liberdade pressupõe uma sensação de paz. O pensamento liberal condena qualquer tipo de medida ou ação que coloque em risco o sossego da humanidade, uma vez que diminuem a possibilidade de cooperação social e de divisão do trabalho.

O sistema capitalista baseia-se na liberdade, a qual se vincula à esfera do livre mercado. Para o liberalismo clássico, ela se apresenta como um mecanismo fundamental, na medida em que assegura um livre funcionamento das relações de compra e venda, bem como uma maior produtividade do trabalho humano, isto é, da exploração deste. O ordenamento da sociedade, conforme Hayek, não deve ser concebido visando uma finalidade, mas sim regido por leis naturais, advindas de maneira espontânea da concorrência (MARTINS, 2009). Nesse sentido, prevalecem sempre aqueles indivíduos que foram e são capazes de produzir algo melhor e mais barato e que atenda às necessidades do consumidor, estimulando o processo de competição.

Nessa perspectiva do liberalismo, o conceito de liberdade é instituído como algo neutro e sem qualquer sentido histórico. A liberdade, assim como a propriedade, é um direito que nasce com os indivíduos, constituindo-se como elemento essencial a natureza humana. Esse estado de espírito pode ser encontrado nos homens alienados no que diz respeito às relações sociais.

Para Martins (2009, p. 40), a liberdade, ao contrário do pensamento liberal, "é uma atividade histórica condicionada pela forma de produção coletiva da existência", definida pelas "condições materiais e culturais da totalidade". Nesse sentido, podemos depreender que numa sociedade capitalista "a liberdade significa o direito a ser explorado, para os que vendem a força de trabalho, e a ser explorador, para os que detêm os meios de produção".

Por assim dizer, obter liberdade sem, contudo, superar as forças produtivas que alimentam o capital é cair na ilusão do real ou na "pseudoconcreticidade", segundo Kosík (1976). Ou seja, é impossível atingi-la numa sociedade onde o capitalismo molda o seu processo.

$\mathrm{O}$ quarto, e o último princípio, diz respeito à minimização da intervenção estatal. $\mathrm{O}$ Estado para o neoliberalismo se apresenta como uma instância social dotada de características de um "sujeito", desvinculada das relações sociais, com interesses e iniciativas próprias, mas que possui um poder limitado frente ao protagonismo do mercado. É uma esfera que tem como função garantir a paz, a liberdade e o direito a propriedade. Martins (2009) ainda complementa:

Sua gênese estaria ligada à ideia de um "acordo" entre indivíduos no sentido de preservação desses direitos. Sua estrutura corresponderia mais especificamente à ideia de governo. Sua função seria a de preservar um ambiente de liberdades de escolhas e, quando necessário, empregar o uso legítimo da força para defesa do indivíduo autônomo e do mercado (p. $40)$.

Diante do que já foi dito em relação às criticas dirigidas à teoria keynesiana, constatamos que o pensamento liberal não admite que o Estado, enquanto setor público, tenha a responsabilidade de intervir em quaisquer problemas sociais, sejam eles de natureza econômica ou política. Essa perspectiva de Estado coaduna com a ideia de que a sua função deve ser reduzida a normas aplicáveis em determinadas situações. Na verdade, o que é proposto não é o fim da planificação estatal ou ausência de mecanismos de intervenção, mas um Estado com funções específicas, direcionado a criar condições ideais 
de "livre concorrência" entre os indivíduos e de liberdade para o mercado (MARTINS, 2009), balizando a sociabilidade segundo o postulado da economia burguesa.

A aparelhagem estatal passa a ser moldada de acordo com as necessidades exigidas pelo mercado que é, segundo a perspectiva neoliberal, o condutor e o principal articulador da dinâmica social capitalista. Ao invés de atuar diretamente sobre a sociedade, sua ação seria pautada em reproduzir apenas os interesses das classes sociais hegemônicas numa determinada ordem social, concedendo um leque maior de liberdade de escolhas para os indivíduos (MARTINS, 2009). Sendo assim, se for garantida a liberdade de agir por conta própria e o Estado diminuir seus gastos sociais, deixando a cargo do mercado, cada sociedade poderá atingir seu pleno desenvolvimento econômico e, consequentemente, o "bem-estar" de todos.

$\mathrm{Na}$ linha proposta, assinalamos a seguinte perspectiva: a plena intervenção estatal e os seus gastos dispensados aos trabalhadores se constituem como fatores do desequilíbrio do sistema capitalista de produção, visto como uma ameaça à liberdade econômica e política da sociedade. Para os neoliberais, os problemas enfrentados pelas sociedades ocidentais nos últimos tempos não seriam efeitos do próprio modelo capitalista, mas da ineficiência e da atuação equivocada do Estado. Isso porque para eles o mercado é muito mais eficaz do que a aparelhagem estatal, pois obtém melhores resultados com o mínimo de custo.

A política neoliberal defende um "Estado mínimo" nas funções sociais para os trabalhadores e forte para o capital, com estabilidade econômica e, principalmente, sem a participação dos sindicatos. De acordo com Anderson (2010, p. 11), "a ideia é manter um Estado forte, sim, em sua capacidade de romper o poder dos sindicatos e no controle do dinheiro, mas parco em todos os gastos e nas intervenções econômicas".

Dessa forma, a política neoliberal propõe integralmente o corte dos gastos com políticas sociais e com o funcionamento do Estado para tal fim, ao passo que o investimento no campo econômico se torna essencial para o fortalecimento do capital financeiro. Ou seja, os direitos sociais, como saúde, educação, segurança, alimentação, dentre outros, são transferidos para o âmbito do mercado. É uma nova configuração societária, mas que continua privilegiando os interesses das frações burguesas em detrimento das necessidades da classe trabalhadora.

De acordo com a concepção liberal, esse Estado capitalista somente atua sobre a ordem social quando a mesma é ameaçada. Nesse caso, são utilizadas medidas coercitivas como forma educativa de conformar e atomizar os indivíduos de modo a preservar a natureza da sociedade.

Diante desses preceitos relatados acima, verificamos que o Estado capitalista tem a função educativa de “adequar a 'civilização' e a moralidade das mais amplas massas populares às necessidades do contínuo desenvolvimento do aparelho econômico de produção e, portanto, de elaborar também fisicamente tipos novos de humanidade" (GRAMSCI, 2012, p. 23), visando à reprodução e manutenção da ordem vigente.

Assim, em termos práticos, esses fundamentos procuram orientar a elaboração teórica e a intervenção prática das diretrizes neoliberais no sentido de propiciar uma nova sociabilidade burguesa. Assentam-se, portanto, em um padrão único de concepção de mundo que se realiza atendendo as necessidades econômicas e políticas da classe dominante, ao mesmo passo em que tais preceitos também oferecem mecanismos para orientar o processo de trabalho e organizar um projeto de educação face às necessidades do capital. 


\section{A reestruturação produtiva e seus impactos no processo de trabalho e na educação: implicações para a formação humana}

Segundo Oliveira (2010), a reestruturação produtiva consistiu em um dos processos que integrou a mundialização do capital, estando relacionada especificamente a face econômica da segunda.

A reestruturação produtiva abarcou profundas alterações na forma de organização do trabalho, sendo introduzidas mudanças substanciais na coordenação da produção que assinalaram para um patamar superior de inserção científica no conjunto das atividades econômicas, sociais e políticas (NEVES, 1994). Uma das expressões significativas de tal processo foi a "substituição" do padrão produtivo "Taylorista/Fordista" pelas formas produtivas flexibilizadas e desregulamentas, sendo estas representas pela "Acumulação Flexível/Toyotismo" (ANTUNES, 2001).

A origem do fordismo/taylorismo remonta o início do século XX, especificamente em 1913, sendo esse modelo criado pelo industrial Henry Ford. O fordismo ${ }^{7}$ tem como fundamentos centrais a hierarquização da estrutura organizacional, a pormenorização do trabalho e a produção mecanizada (ANTUNES, 2001). Segundo Gounet (1999), ele se baseia nos "métodos tayloristas" que têm por finalidade propiciar um consumo de massas utilizando tempo reduzido e menor custo.

A acumulação flexível/toyotismo ${ }^{8}$, por sua vez, é decorrente das novas relações sociais capitalistas construídas no mundo a partir da década de 1970, sendo esta conjuntura marcada pela ruptura do consenso keynesiano e pelo aprofundamento e superação do modelo de produção fordista (MELO, 2004). Este padrão de produção consiste numa nova organização dita flexível e integrada do trabalho, sendo caracterizado pela introdução de novas tecnologias microeletrônicas e da informática na produção, bem como da incorporação de métodos mais racionalizados no âmbito da organização do trabalho (NEVES, 1994).

O regime de acumulação flexível, segundo Melo (2004), se realiza em consonância com a ideologia neoliberal e com a mundialização do capital. Esta nova forma de organização da produção e do trabalho vai se consolidar em âmbito mundial, ultrapassando os limites da indústria automobilística e perpassando os diversos setores sociais.

Sobre este modelo, David Harvey afirma que:

A acumulação flexível [...] é marcada por um confronto direto com a rigidez do fordismo. Ela se apóia na flexibilidade dos processos de trabalho, dos mercados de trabalho, dos produtos e padrões de consumo. Caracteriza-se pelo surgimento de setores da produção inteiramente novos, novas maneiras de fornecimento de serviços financeiros, novos mercados e, sobretudo, taxas altamente intensificadas de inovação comercial, tecnológica e organizacional. A acumulação flexível envolve rápidas mudanças nos padrões do desenvolvimento desigual, tanto entre setores, como entre regiões geográficas, criando, por exemplo, um vasto movimento no emprego no chamado 'setor de serviços', bem como conjuntos industriais completamente novos em regiões até então subdesenvolvidas [...] (HARVEY, 1992, p. 140-141 apud MELO, 2004, p. 152-153).

Constata-se que a noção de flexibilidade é o eixo central do padrão da acumulação flexível, visto que o mesmo advoga ser necessário a flexibilidade do aparato produtivo bem como a flexibilização dos trabalhadores, objetivando através disto "alcançar o máximo de 
produtividade da força de trabalho com um mínimo de custo, ou seja, um processo de superexploração da força de trabalho para ampliar a taxa de mais-valia e de lucro [...]" (BEHRING, 2008, p. 40).

Esta forma "flexibilizada" de acumulação capitalista trouxe impactos significativos para o mundo do trabalho, para a educação escolar e para a subjetividade do sujeito. Com relação ao primeiro, destaca-se que a atividade humana assume a forma de "trabalho explorado"/"trabalho alienado" na configuração do capitalismo contemporâneo.

A dimensão da exploração, segundo Gounet (1999), se dá a partir de três formas principais, quais sejam: (1) intensificação da atividade humana; (2) redução de salários e degradação da proteção social e (3) fragmentação da consciência de classe dos trabalhadores.

A primeira ocorre através da sobrecarga do trabalho dos sujeitos, que devem ser mais rápidos e "eficientes", reduzindo os "tempos mortos" no processo de produção (GOUNET, 1999). A intensificação poderá ocorrer através de duas vias: pelo aumento de tarefas durante as horas próprias do serviço ou pela extensão da jornada diária da atividade.

A segunda via de exploração ocorre através da redução de salários e da degradação da proteção social, uma vez que o modelo da automação flexível atribui grande ênfase aos regimes e contratos de trabalho ditos "flexíveis", a redução do emprego regular em detrimento do trabalho em tempo parcial e a terceirização. Segundo Behring (2008), estes novos regimes e contratos de trabalho advindo da reestruturação produtiva, implicam a perca de direitos por parte dos trabalhadores, ainda que estes sejam limitados e resultantes de lutas entre classes e frações de classe no decurso da história, bem como significam o retrocesso da luta sindical.

A terceira forma de exploração do trabalho está relacionada à fragmentação da consciência de classe dos trabalhadores. Segundo Behring (2008), a "organização do trabalho na revolução tecnológica em curso é desagregador da solidariedade de classe e regressivo" (p. 37). Assim, verifica-se que a atual configuração do trabalho e da produção, a classe dominante impõe tendências neocorporativas e individualistas ancoradas na lógica de reprodução do capital, as quais se configuram em obstáculos para a constituição de uma classe para si por parte dos trabalhadores. Ocorre, pois, uma "fratura de identidades" (BEHRING, 2008, p. 37), que é promovida pela condição de precariedade a qual o operário está submetido nesta nova fase de internacionalização do capital.

O trabalho também se configura por ser alienado, uma vez que na sociedade atual, a apropriação dos produtos da atividade humana acontece a partir de uma forma social que aliena os produtos da classe que os produz. Segundo Marx:

[...] o trabalho é externo ao trabalhador, quer dizer, não pertence a seu ser; que em seu trabalho não se afirma, mas se nega; não se sente feliz, mas infeliz, não desenvolve uma livre energia física e espiritual, mas mortifica seu corpo e arruína seu espírito. Por isso o trabalhador só se sente em si fora do trabalho, e no trabalho se sente fora de si. Está em sua casa quando não trabalha e quando trabalha não está em sua casa. Seu trabalho não é, assim, voluntário, mas forçado, trabalho forçado. Por isso não é a satisfação de uma necessidade, mas somente um meio para satisfazer as necessidades fora do trabalho (MARX, 1985, p. 108-109 apud SAVIANI, 2009, p.428).

Neste sentido, verificamos que o trabalhador não se afirma nem se reconhece no processo e nos resultados de seu trabalho, sentindo-se infeliz e externo a ele. Ao invés desta atividade humana permitir o desenvolvimento de todas as potencialidades criativas 
do sujeito, permitindo sua emancipação, nas sociedades capitalistas ele mortifica o homem, degradando as condições de existência do mesmo.

A acumulação flexível também trouxe impactos para o campo educacional, visto que estando a educação e a escola inseridas na atual fase de internacionalização do capital, estas sofrem influências políticas e ideológicas do projeto neoliberal. Com relação específica a administração escolar, verificamos a repercussão dos preceitos e das orientações formativas do capital no âmbito da escola, o que pode ser comprovado através da transferência da gestão empresarial, forma de organização característica do atual modelo de produção vigente, para o campo da educação escolar, corroborando para o gerencialismo educacional.

A gestão empresarial se baseia no preceito geral da acumulação do capital, qual seja: aumento da eficiência/produtividade visando à mais-valia. Sua função consiste no controle do trabalho alheio, objetivando a obtenção do lucro, assim ela coordena o esforço humano coletivo através do controle externo para o alcance deste objetivo (PARO, 2001).

Percebemos que a lógica empresarial é incompatível com a lógica escolar pautada na transformação social, visto que diferentemente da empresa que produz objetos/mercadorias em curto prazo, o "produto" da escola caracteriza-se por ser de longo prazo, sendo ele o "aluno educado, ou o aluno com a 'porção' de educação que se objetivou alcançar no processo" (PARO, 2000, p. 302). Logo, cabe afirmar que enquanto as ações empresariais têm como parâmetro o mercado e o capital, a escola, por sua vez, deveria eleger o ser humano como medida de todos os processos educacionais (FRIGOTTO, 2002).

Mesmo sendo os objetivos e as finalidades de tais organizações sociais antagônicas, constatamos que na fase do capitalismo contemporâneo a escola passa a estruturar a sua organização a partir desta lógica empresarial. Assim, verificamos que o trabalho pedagógico desenvolvido nas escolas a partir das reformas de ensino na década de 1990, passou a se orientar com o objetivo de fornecer as competências e as habilidades demandadas pelo mercado de trabalho na atualidade, tendo como norte a formação do trabalhador de novo tipo, o qual deveria ser formado a partir da noção de empregabilidade. ${ }^{9}$

O papel do diretor nesta configuração de gestão empresarial é central, visto que igualmente nas empresas, ele deverá assumir a função de gerente educacional, se constituindo enquanto um sujeito motivador do trabalho em equipe, que deve apresentar soluções ditas inovadoras, estabelecer metas/prazos e valorizar a meritocracia (OLIVEIRA, 2008).

Neste sentido, averiguamos que as orientações neoliberais que subsidiam a reestruturação produtiva advogam a favor da conversão da prática educativa para o âmbito do mercado. É defendida a transferência da esfera política da educação para a esfera do mercado, sendo necessários os seguintes objetivos:

Dois grandes objetivos dão coerência e atravessam horizontalmente tais estratégias: a) a necessidade de estabelecer mecanismos de controle de qualidade (na ampla esfera dos sistemas educacionais e, de modo específico, até o interior das próprias instituições escolares); e b) a necessidade de articular e subordinar à produção do sistema educacional as demandas que o mercado de trabalho formula (GENTILI, 1988, p.18).

Assim, para a lógica burguesa é o mercado e suas demandas quem deve orientar as práticas educativas e controlar a política educacional. A escola deverá estar centrada em uma lógica interinstitucional, flexível e meritocrática, valorizando a competição entre os 
sujeitos. Tais orientações vão implicar consequências para a educação, quais sejam: (1) destituição da educação enquanto um direito público a ser assegurado pelo Estado; e (2) redução da educação a uma mercadoria, visto que à medida que ela se transforma em serviço a ser oferecido pelos empresários, eles transferirão os padrões impostos pelo mercado para a prática educativa (OLIVEIRA, 2006).

No que cabe às implicações para a subjetividade do sujeito, Sennett (2007) afirma que a reestruturação produtiva traz repercussões que incidem no caráter subjetivo do trabalhador, ocorrendo uma redefinição do mesmo. O caráter, segundo este mesmo autor, se caracteriza por ser uma construção de "longo prazo" que os homens realizam a partir das relações sociais estabelecidas, sendo, portanto, o "o valor ético que atribuímos aos nossos próprios desejos e às nossas relações com os outros" (SENNETT, 2007, p. 10).

Com a mundialização do capital, tais relações de "longo prazo" estão sendo tencionadas pelas de "curto prazo", estando elas em sintonia com a noção de flexibilidade. O discurso neoliberal advoga que estamos vivendo em tempos casuais (e não intencionais) de "incertezas", sendo imprescindível estabelecer outras maneiras de organizar o tempo, em especial o tempo do trabalho, o que seria possível através da adoção do lema "Não há longo prazo" (SENNETT, 2007). Esta noção, por sua vez, faz com que as relações interpessoais estabelecidas se tornem fluídas e incompletas, estimulando o individualismo exacerbado e a degradação da vida em casos mais extremos.

Diante do exposto, verificamos que a formação humana advinda da nova configuração do trabalho na contemporaneidade está atrelada à necessidade básica do capitalismo em garantir a formação de um trabalhador de novo tipo tanto no plano técnico como no ético-político (NEVES, 2005). Este, por sua vez, deverá se configurar enquanto um sujeito flexível, polivalente e adaptado às demandas capitalistas impostas pela reestruturação produtiva (BEHRING, 2008). A formação está pautada não na emancipação do homem e no desenvolvimento pleno do sujeito, tal como defende a perspectiva marxista, mas na formação de pessoas acríticas e adaptadas ao capital (ASBAHR; SANCHES, 2006).

\section{Finalizando}

A nova fase de internacionalização capitalista, expressada pela mundialização do capital, trouxe novas demandas para o processo de produção e para a formação humana. $\mathrm{Na}$ atualidade, a produção da existência humana, que envolve a dimensão material e imaterial, está condicionada aos preceitos e valores desta nova conjuntura da acumulação do capital, a qual elegeu o neoliberalismo como a base político-ideológica de sociedade.

A mundialização do capital se consistiu em um processo intencional e não casual, como advoga o discurso dominante, ou seja, ela foi requerida e realizada a partir de estratégias burguesas com o intuito de consolidar na realidade concreta um novo projeto de sociabilidade, o qual passou a educar o conjunto da sociedade para que esta passasse a sentir/pensar/agir em conformidade com a concepção de mundo dominante.

$\mathrm{Na}$ contemporaneidade, as atividades humanas referentes ao trabalho e a educação foram redefinidas em consonância com o projeto hegemônico de sociedade e de educação, logo ambas as atividades assumiram formas distintas e até mesmo antagônicas as suas concepções ontológicas. O trabalho enquanto prática social, que tem a potencialidade de humanizar os sujeitos, assume um caráter de exploração e de alienação, estando a serviço da classe burguesa no aumento da produtividade e na extração da mais-valia. E a educação, enquanto ato formativo que decorre do e se orienta pelo processo de trabalho passa, na 
sociedade capitalista, a ser vista como um meio estratégico a serviço da burguesia no processo de dominação.

Para que a formação do trabalhador de novo tipo requerido pelo capital seja assegurada se faz imprescindível uma gestão escolar que molde os sujeitos em conformidade com as demandas do atual contexto capitalista, ou seja, que forme o trabalhador flexível, polivalente e com predisposição para a aprendizagem por longo de toda a vida (OLIVEIRA, 2010). Isso é potencializado pela gestão empresarial que adveio da mundialização do capital e mais especificamente da forma de coordenação do esforço humano coletivo no processo de reestruturação produtiva.

Verificamos, pois, que os preceitos e valores inerentes a mundialização do capital exercem grande interferência sobre o trabalho e a prática educativa, passando a direcionar formas de existência e de subjetividades dos homens na realidade concreta. Porém, partindo das ideias de Saviani (2012) de que a educação possui uma dupla dimensão, ou seja, que ela ao mesmo tempo é determinada pela sociedade e determinante da mesma, tendo a potencialidade de interferir sobre a realidade, torna-se viável pensar em projetos alternativos de educação, os quais deverão estar comprometidos com uma sociedade efetivamente igualitária e democrática, com vistas a extinguir qualquer forma de dominação de classes.

Em última análise, ressaltamos que o papel do conhecimento historicamente acumulado e sistematizado torna-se fundamental na busca deste ideal, pois, somente através dele a classe trabalhadora tem a possibilidade de se emancipar da dominação capital, bem como propor juntamente com os demais seguimentos da sociedade, projetos que busquem alternativas ao modelo burguês de educação.

\section{Referências}

ANDERSON, Perry. Balanço do neoliberalismo. In: SADER, Emir; GENTILI, Pablo (Org.). Pós-neoliberalismo: as políticas sociais e o Estado democrático. Rio de Janeiro: Paz e Terra, 2010. p. 66-86.

ANTUNES, Ricardo. Trabalho e precarização numa ordem neoliberal. In: GENTILI, Pablo; FRIGOTTO, Gaudêncio (Org.). A cidadania negada: políticas de exclusão na educação e no trabalho. São Paulo: Cortez; Buenos Aires, Argentina: CLACSO, 2001. p. 35-48.

ASBAHR, Flávia da Silva Ferreira; SANCHES, Ydeliz Coelho de Souza. Transformação social: uma possibilidade da educação escolar? In: PARO, Vitor Henrique (Org.). A teoria do trabalho em Marx e a educação. São Paulo: Cortez, 2006. p. 57-77.

BEHRING, Elaine Rosseti. Brasil em contra-reforma: desestruturação do Estado e perda de direitos. 2. ed. São Paulo: Cortez, 2008.

BIANCHETTI. Roberto. Modelo neoliberal e políticas educacionais. 4. ed. São Paulo: Cortez, 2005

DUARTE, Newton. Sociedade do conhecimento ou sociedade das ilusões? Quatro ensaios crítico-dialéticos em filosofia da educação. Campinas, São Paulo: Autores Associados, 2003.

FRIGOTTO. Gaudêncio. Educação e a construção democrática no Brasil- Da ditadura civil-militar à ditadura do capital. In: FÁVERO, Osmar; SEMERARO, Giovanni (Org.). Democracia e construção do público no pensamento educacional brasileiro. Petropólis, RJ: Vozes, 2002. p. 53-67 
FRIGOTTO, Gaudêncio. Novos fetiches mercantis da pseudoteoria do capital humano no contexto do capitalismo tardio. In: ANDRADE, Juarez de; PAIVA, Lauriana Gonçalves de (Org.). As políticas públicas para a educação no Brasil contemporâneo: limites e contradições. Juiz de Fora: Ed. UFJF, 2011. p. 18-36

GENTILI, Pablo. Pedagogia da democracia mínima (O consenso como simulacro). In: A falsificação do consenso: simulacro e imposição na reforma educacional do neoliberalismo. Petrópolis, RJ: Vozes, 1998. p. 40-71

GROS, Denise Barbosa. Institutos liberais e neoliberalismo no Brasil da Nova República. 2003. Tese (Doutorado em Ciência Política)-Departamento de Ciência Política Universidade Estadual de Campinas, Campinas, 2003.

GOUNET. Thomas. Fordismo e Toyotismo na civilização do automóvel. São Paulo: Bontempo, 1999.

HOBSBAWM, Eric John Ernest. A era dos extremos, o breve século XX: 1914-1991. 2. ed. Trad. Marcos Santarrita. São Paulo: Companhia das Letras, 1995.

KOSIK, Karel. Dialética do concreto. Rio de Janeiro: Paz e Terra, 1976.

MARTINS, André Silva; LIMA, Katia Regina de Souza. Pressupostos, princípios e estratégias. In. NEVES, Lúcia Maria Vanderley (Org.). A nova pedagogia da hegemonia. Estratégias do capital para educar o consenso. Coletivo de Estudos de Política Educacional. São Paulo: Xamã, 2005. p. 43-67.

MARTINS, André Silva. Burguesia e a nova sociabilidade: estratégias para educar o consenso no Brasil contemporâneo. 2007. Tese (Doutorado em Educação)-Universidade Federal Fluminense, Niterói, RJ, 2007.

MELO. Adriana Almeida Sales de. A mundialização da educação: consolidação do projeto neoliberal na América Latina. Brasil e Venezuela. Maceió: EDUFAL, 2005.

NEVES, Lúcia Maria Wanderley. Educação e política no Brasil de hoje. São Paulo: Cortez, 1994.

NEVES, Lúcia Maria Wanderley (Org.). A nova pedagogia da hegemonia: estratégias do capital para educar o consenso. São Paulo: Xamã, 2005.

NEVES, Lúcia Maria Wanderley; SANT’ANNA, Ronaldo. Introdução: Gramsci, o Estado educador e a nova pedagogia da hegemonia. In: NEVES, Lúcia Maria Wanderley (Org.) A Nova Pedagogia da Hegemonia: estratégias do capital para educar o consenso. Coletivo de Estudos de Política Educacional, SP, Xamã, 2005. p.19-39.

OLIVEIRA, Lilian Haffner da Rocha. A teoria do valor em Marx e a organização do trabalho coletivo na escola: elementos para uma reflexão crítica. In: PARO, Vitor Henrique. A teoria do trabalho em Marx e a educação. São Paulo: Cortez, 2006. p. 77117.

OLIVEIRA, Dalila Andrade; ROSAR, Maria de Fátima Felix (Org.). Política e gestão da educação 2. ed. Belo Horizonte: Autêntica, 2008. p.126-144.

OLIVEIRA, Dalila Andrade. Educação básica: gestão do trabalho e da pobreza. 2. ed. Petrópolis, RJ: Vozes, 2010.

PARO, Vitor Henrique. A gestão da educação ante as exigências de qualidade e produtividade da escola pública. In: SILVA, Luiz Heron da (Org.). A escola cidadã no contexto da globalização. Petrópolis, RJ: Vozes, 2000. p. 300-307

PARO, Vitor Henrique. Administração escolar: uma introdução crítica. São Paulo: Cortez, 2001. 
SAVIANI, Dermeval. Transformações do capitalismo, do mundo do trabalho e da educação. In: LOMBARDI, José Claudinei; SAVIANI, Dermeval ; SANFELICE, José Luis (Org.). Capitalismo, trabalho e educação. Campinas, SP: Autores Associados, HISTEDBR, 2005. p. 13-24. (Coleção Educação Contemporânea).

SAVIANI, Dermeval. Trabalho e educação: fundamentos ontológicos e históricos. In: REUNIÃO DA ASSOCIAÇÃO NACIONAL DE PÓS-GRADUAÇÃO E PESQUISA E EDUCAÇÃO, 29., 2006, Caxambu. Anais... Caxambu: ANPED, 2006. p. 152-165.

SAVIANI, Dermeval. A formação humana na perspectiva histórico-ontológica. In: REUNIÃO DA ASSOCIAÇÃO NACIONAL DE PÓS-GRADUAÇÃO E PESQUISA E EDUCAÇÃO, 32., 2009, Caxambu. Anais... Caxambu: ANPED, 2009. p. 422-433

SAVIANI, Dermeval. Pedagogia Histórico-Crítica: primeiras aproximações. 11. ed. Campinas, SP: Autores associados, 2012.

SENNETT, Richard. A corrosão do caráter: as consequências pessoais do trabalho no novo capitalismo. Tradução de Marcos Santarrita. 12. ed. Rio de Janeiro: Record, 2007.

STEWART JÚNIOR, Donald. O que é liberalismo. 5. ed. aum. Rio de Janeiro: Instituto Liberal, 1995. $118 \mathrm{p}$.

SOUZA, Carlos Eduardo. A política nacional de esporte no Brasil contemporâneo como estratégia para educar o consenso. 2011. Dissertação (Mestrado em Educação)Universidade Federal de Juiz de Fora, Juiz de Fora, MG, 2011.

\section{NOTAS:}

\footnotetext{
${ }^{1}$ Graduada em Pedagogia pela Universidade Federal de Juiz de Fora (UFJF), mestranda em Educação pelo Programa de Pós-Graduação em Educação da UFJF e integrante do Núcleo de Estudos sobre Trabalho e Educação (NETEC)/UFJF.

${ }^{2}$ Graduada em Pedagogia pela Universidade Federal de Juiz de Fora e integrante do Núcleo de Estudos sobre Trabalho e Educação (NETEC)/UFJF.
}

\footnotetext{
${ }^{3}$ Segundo Antunes (2001), a crise estrutural do capital ocorreu em meados da década de 1970 em todo o mundo sobre o conjunto das economias capitalistas. Ela foi marcada por uma intensidade profunda que levou o capital "a desenvolver práticas materiais da destrutiva auto-reprodução ampliada, possibilitando a visualização do espectro da destruição global, em vez de aceitar as necessárias restrições positivas no interior da produção para a satisfação das necessidades humanas" (MÉSZÁROS 1995 apud ANTUNES, 2001, p. 39). Dentre as "respostas" do capital à sua crise, destaca-se às metamorfoses ocorridas no processo de produção na década de 1980, sendo expressa pela reestruturação produtiva.

${ }^{4} \mathrm{O}$ Keynesianismo é uma teoria que defende a atuação direta do Estado nas questões sociais e na economia para o desenvolvimento do capital. Inspirada nas formulações do economista John Maynard Keynes, a doutrina keynesiana, gestada na década de 1930, avançou nos anos de pós Segunda Guerra e conquistou espaço a partir da crise de 1973.

${ }^{5} \mathrm{O}$ Consenso de Washington foi realizado nos EUA no ano de 1989 e reuniu intelectuais latino-americanos, assim como representes do FMI, Bando Mundial e do governo norte-americano com o objetivo principal orientar as economias dos países dependes aos interesses do capital internacional. O Consenso de Washington também buscou analisar as reformas econômicas em cursos na América Latina e assumir um papel de conduzir os governos periféricos para desenvolverem políticas econômicas e sociais de acordo com os preceitos neoliberais.

${ }^{6}$ A noção de responsabilidade social refere-se a uma "ideologia que expressa um encerramento de crise e tensões hegemônicas e indica novas acomodações políticas e novas movimentações qualitativamente superiores que penetram o campo das políticas de Estado e envolvem todas as frações de classe burguesa, reordenando as relações políticas mais amplas localizadas no interior da sociedade civil” (MARTINS, 2005, p. 151).
} 
${ }^{7}$ Segundo Gounet (1999), suas características principais são: (1) produção em massa, implicando racionalizar ao extremo as operações realizadas pelos trabalhadores e o combate às formas de desperdício, inclusive de tempo; (2) parcelamento das tarefas, que implica à segmentação das atividades produtivas, caracterizando o trabalho repetitivo e individualizado; (3) criação da "linha" para promover a ligação entre os diferentes trabalhos, em que esta irá fixar uma cadência regular de trabalho, controlável pela direção da empresa; (4) padronização de peças, objetivando reduzir o trabalho do operário a gestos simples e a evitar o desperdício de adaptação do componente ao automóvel; (5) automatização das fábricas a partir de tecnologias relativamente simples; e (6) o aumento de salários visando aquietar possíveis resistências dos trabalhadores.

${ }^{8}$ Segundo Gounet (1999), as origens desse modelo se referem a sua implantação pioneira no Japão, na fábrica da Toyota, durante as décadas de 1950 a 1970. Suas características centrais são: (1) produção variada e heterogênea, sendo ancorada pela demanda e o crescimento, pelo fluxo; (2) combate às formas de desperdício; (3) flexibilidade da organização do trabalho bem como dos trabalhadores; (4) horizontalidade da estrutura organizacional; (5) melhor aproveitamento do tempo e da produção bem como a redução ao extremo do tempo de não-produção; (6) produção baseada na diversidade e em série reduzida; e (7) trabalho pautado em equipe.

${ }^{9}$ Segundo Leite (1997 apud OLIVEIRA, 2010, p. 249) o conceito de empregabilidade "refere-se à capacidade dos trabalhadores de se manterem empregados ou encontrar novos empregos, quando demitidos, a partir de suas possibilidades de resposta às exigências de maiores requisitos de qualificação demandados pelas mudanças tecnológicas do processo produtivo". Em essência, segundo Frigotto (2011), poder-se-ia afirmar que esta noção tem por objetivo extinguir o direito dos trabalhadores ao pleno emprego, ocasionando a intensificação e a exploração do trabalho. 